\title{
Development and Body Composition of Quarter Horse Foals during Nursing
}

\author{
Monica Miranda Hunka, Helena Emília Cavalcanti da Costa Cordeiro Manso, \\ Ramona Bastos Bernardo, Elizabeth Regina Rodrigues da Silva, \\ Lúcia Maia Cavalcante Ferreira, Hélio Cordeiro Manso Filho* \\ Núcleo de Pesquisa Equina, Departamento de Zootecnia, Universidade Federal Rural de Pernambuco, \\ Recife, Brazil \\ Email: ${ }^{*}$ hmanso@dz.ufrpe.br
}

Received 2 October 2014; revised 3 November 2014; accepted 14 November 2014

Copyright (C) 2014 by authors and Scientific Research Publishing Inc.

This work is licensed under the Creative Commons Attribution International License (CC BY). http://creativecommons.org/licenses/by/4.0/

(c) (i) Open Access

\section{Abstract}

The monitoring and development of foals, based on biometric indices, and the determination of body composition could be important for genetic improvement and the elaboration of nutritional plans for horses. Considering that little information was available, the aim of the present study was to assess the growth and determine the body composition of suckling Quarter Horse foals. Animals $(n=46)$ of both sexes were monitored monthly from birth until the fifth month of age, using an ultrasound device and the following measurements: Wither Height (WH); Chest Perimeter (CP); Cannon Bone Circumference (CBC) Cannon Bone Girth (CG); Body Mass (BM); and Rump Fat Thickness (RFT). These tests determined the Fat-Free Mass (FFM), BM, Fat Percentage (FP) and Fat Thickness (FT). The data were analyzed using ANOVA and Tukey's test, with differences considered statistically significant when $P \leq 0.05$. The results demonstrated that the parameters analyzed changed significantly during the study period. The BM was $\sim 41$ at birth and $\sim 177 \mathrm{~kg}$ at the point of weaning. Conversely, the FM was $\sim 3.8$ at birth and $18.1 \mathrm{~kg}$ at the point of weaning. The FFM was $\sim 37$ and $\sim 160 \mathrm{~kg}$ at the time of birth and weaning, respectively. The FP varied from 9.3 at birth to 9.54 at weaning. The mean FT was $\sim 1.39$ and $\sim 1.91 \mathrm{~cm}$ at birth and weaning, respectively. The WH measured $\sim 91$ at birth and $116 \mathrm{~cm}$ at weaning. In conclusion, suckling foals gain BM quickly from the time of birth to the time of weaning. The main cause of this gain is FFM. Therefore, due to the significant changes in the parameters studied herein, it is important to monitor these values in order to prevent nutritional imbalances.

\section{Keywords}

Body Mass, Fat-Free Mass, Fat Percentage, Horse, Ultrasound

\footnotetext{
${ }^{*}$ Corresponding author.
}

How to cite this paper: Hunka, M.M., Manso, H.E.C.C.C., Bernardo, R.B., da Silva, E.R.R., Ferreira, L.M.C. and Filho, H.C.M. (2014) Development and Body Composition of Quarter Horse Foals during Nursing. Open Journal of Veterinary Medicine, 4, 276-280. http://dx.doi.org/10.4236/ojvm.2014.411033 


\section{Introduction}

The growth and development of foals are directly related to genetic potential and other factors such as nutrition and exercise, which are regulated by hormonal control. These parameters should be in equilibrium to ensure a satisfactory performance on behalf of the animal during its adult life. It is an important highlight that alterations in these processes may lead to economic losses and inappropriate animal welfare.

Inadequate rearing and nutritional imbalances can cause several abnormalities in the development of foals, including poor bone formation, severe limb deviation and joint abnormalities. Therefore, knowledge of the development of foals could be important for nutritional and breeding plans. In addition, it could indicate the athletic potential of these animals in adulthood, which favors analysis and adjustments to the variables that impair the appropriate growth of the foal.

Many horse breeds have different abilities in terms of force, speed and endurance. These characteristics are directly related to patterns of development. Therefore, comparative studies are needed. According to the Brazilian Association of Quarter Horse Breeders (ABQM), there are 4,000,000 individuals of this breed throughout the world, about 350,000 of which can be found in Brazil. This horse breed is extremely versatile, participating in several sports, including racing and vaquejada (a Brazilian form of bullfighting, performed on horseback). Therefore, knowledge of the body composition of these animals is essential for breed selection, since animals with a greater capacity for muscle accumulation exhibit a better athletic performance.

Little information is available about the body composition of horses. Recently, it has been demonstrated that young animals (less than 18 months old) exhibit a Body Fat Percentage (BFP) of 10.4\% [1], although these authors did not assess the animals during the lactation period. Over the years, the development of horses has been assessed based on weight gain and biometric indices. However, with the reduced costs of ultrasound devices, this method is becoming feasible for the determination of body composition. Fat Thickness (FT) and muscle area have already been well documented in other animal species. This method is precise and easy to apply for technicians involved in horse breeding. It could be used as an additional tool to monitor the development of these animals. The relationship between Rump Fat Thickness (RFP) and the body composition of horses was previously determined [2].

Considering the lack of information about suckling foals, the aim of this study was to assess the development and body composition of Quarter Horse foals in Brazil, thereby assisting the appropriate rearing of these animals.

\section{Material and Methods}

This study was conducted on the Uberaba Farm, located in the municipality of Lagoa do Carro $\left(07^{\circ} 5^{\prime} 41^{\prime \prime} S\right.$ $\left.35^{\circ} 19^{\prime} 11 " W\right)$, Pernambuco, Brazil. Suckling Quarter Horse foals $(n=46)$, of both sexes, that were born between July 2011 and January 2012 were used. Foals were reared in a semi-intensive system, together with the mares. A creeper system was used to provide extruded commercial diet (Guabi ${ }^{\circledR}$ Equitage Potro E, $19 \%$ crude protein, 5\% ether extract and $3.45 \mathrm{Mcal} / \mathrm{kg}$ of digestible energy) ad libitum. The foals had free access to water and mineralized salt. They were kept with their mothers in pastures of Massai grass (Panicum maximum cv. Massai) and Tifton grass (Cynodon dactylon cv. Tifton 68). The mares had free access only to the pasture.

The assessments were performed at different time points: on the day of the animal's birth and after 30, 60, 90, 120 and 150 (weaning) days of life. The following parameters were analyzed: Wither Height (WH) (obtained with a hipometer); Chest Perimeter (CP) and Cannon Bone Circumference (CBC) (obtained with tape measure), Body Mass (BM) (obtained through weighing scale) and Rump Fat Thickness (RFT) obtained by ultrasound, using equipment for veterinary use (Shenzhen Mindray DP-2200Vet model) with a linear transducer of 5.0 MHz.

Fat Thickness (FT) was measured by placing the transducer on the midline between the end of the ileum and the tip of the ischium, about 8 centimeters from the midline of the body. Thus, the subcutaneous fat was visualized and the BFP was determined according to the method previously described (i.e., BFP = 8.64 + 4.7 FT) [2].

Once the BFP had been obtained, Fat Mass (FM) and Fat-Free Mass (FFM) were calculated in kilograms. For this assessment, previous BM data (kilograms) are necessary (i.e., $\mathrm{FM}=\mathrm{BFP} \times \mathrm{BM} ; \mathrm{FFM}=\mathrm{BM}-\mathrm{FM}$ ).

The data were analyzed using ANOVA, with one factor for repeated measures, and Sigma Sat3.0 software. Afterwards, the differences between the mean values were identified using Tukey's test. In both tests, the significance level was set at $5 \%$. The results are presented as mean and standard deviation values. 


\section{Results}

The mean and standard deviation values are displayed in Table 1. A high accumulation of BM, followed by accumulation of FM and FFM, was observed. The gains recorded for BM, FM and FFM from birth to weaning were 135.9, 13 and $123 \mathrm{~kg}$, respectively.

The Average Daily Gain (ADG) from birth to weaning was about 960 grams/day. From birth to the first month, the ADG was $1180 \mathrm{~g} /$ day. These data demonstrated the importance of milk in the nutrition of the neonate. Therefore, nutritional stress in this period of life may be reflected in a reduction of the animal's performance in the future.

The mean BM value of foals at birth was 41 kg. The following BM gains were recorded: $99 \%$ from birth to the first month of life; 34\% between the first and second months; $23 \%$ between the second and third months; $19 \%$ from the third to the fourth months; and 10\% until the fifth month. The gains of FM and FFM from birth to weaning were $\sim 123$ and $13 \mathrm{~kg}$, respectively.

The biometric indices differed significantly between the time of birth and the time of weaning (Table 2). In addition, an increase of $~ 56 \%, ~ 28 \%$ and $~ 26 \%$ was observed for CP, CG and WH, respectively.

\section{Discussion}

This study determined the growth parameters of suckling Quarter Horse foals for the first time in Brazil. The animals used herein were reared under typical conditions, grazing in pastures with unlimited exercise. Males and females were not separated for the statistical analysis, since suckling foals do not receive different nutritional treatment in field conditions. Moreover, this variable did not vary statistically in previous studies. Significant differences were detected for the BM, FM and FFM throughout the study period, demonstrating that the animals were growing up. Usually, foals with normal development double in weight in the first month of life [3]. At weaning age, their body weight should be five times greater than their birth weight. The values reported herein are within the values reported in the literature. The ADG was highest in the first month of life, which corresponds to the period of high availability of energy, provided by the mare's milk [4]. It is known that during the

Table 1. Body Mass, Fat Percentage and Fat Thickness of Quarter Horse suckling foals (from birth to weaning).

\begin{tabular}{ccccccc}
\hline \multirow{2}{*}{ Evaluations } & \multicolumn{5}{c}{ Time-points } \\
\cline { 2 - 6 } & At birth & 1st month & 2nd month & 3rd month & 4th month & 5th month \\
\hline BM (kg) & $40.9 \pm 0.9^{\mathrm{f}}$ & $81.5 \pm 1.9^{\mathrm{e}}$ & $109.4 \pm 2.6^{\mathrm{d}}$ & $134.8 \pm 3.1^{\mathrm{c}}$ & $160.7 \pm 3.4^{\mathrm{b}}$ & $176.8 \pm 3.1^{\mathrm{a}}$ \\
FFM (kg) & $37.0 \pm 0.8^{\mathrm{f}}$ & $73.9 \pm 1.7^{\mathrm{e}}$ & $99.0 \pm 2.4^{\mathrm{d}}$ & $119.4 \pm 3.9^{\mathrm{c}}$ & $145.4 \pm 3.1^{\mathrm{b}}$ & $160.0 \pm 2.8^{\mathrm{a}}$ \\
FM (kg) & $3.8 \pm 0.1^{\mathrm{f}}$ & $7.6 \pm 0.2^{\mathrm{e}}$ & $10.3 \pm 0.2^{\mathrm{d}}$ & $12.7 \pm 0.3^{\mathrm{c}}$ & $15.2 \pm 0.3^{\mathrm{b}}$ & $16.8 \pm 0.3^{\mathrm{a}}$ \\
BFP (\%) & $9.30 \pm 0.2^{\mathrm{f}}$ & $9.37 \pm 0.02^{\text {def }}$ & $9.41 \pm 0.2^{\mathrm{bcde}}$ & $9.44 \pm 0.02^{\text {abcd }}$ & $9.48 \pm 0.02^{\text {abc }}$ & $9.52 \pm 0.03^{\text {ab }}$ \\
FT (cm) & $1.39 \pm 0.4^{\mathrm{f}}$ & $1.55 \pm 0.04^{\text {def }}$ & $1.64 \pm 0.03^{\text {bcde }}$ & $1.70 \pm 0.04^{\text {abcd }}$ & $1.80 \pm 0.05^{\text {abc }}$ & $1.87 \pm 0.06^{\text {ab }}$ \\
ADG (kg/d) & - & $1.18 \pm 0.08^{\mathrm{a}}$ & $0.87 \pm 0.07^{\mathrm{b}}$ & $0.85 \pm 0.08^{\mathrm{b}}$ & $0.68 \pm 0.08^{\mathrm{b}}$ & $0.41 \pm 0.10^{\mathrm{c}}$ \\
\hline
\end{tabular}

Note: means in the same line followed by different letters indicate statistical difference $(P<0.05)$ through the Tukey's test. BM: Body Mass; FFM: Fat-Free Mass; FM: Fat Mass; BFP: Body Fat Percentage; FT: Fat Thickness; ADG: Average Daily Gain.

Table 2. Biometric indices of Quarter Horse suckling foals (from birth to weaning).

\begin{tabular}{|c|c|c|c|c|c|c|}
\hline \multirow{2}{*}{$\begin{array}{l}\text { Biometricindices } \\
(\mathrm{cm})\end{array}$} & \multicolumn{6}{|c|}{ Time-points } \\
\hline & At birth & 1st month & 2nd month & 3rd month & 4th month & 5th month \\
\hline WH & $90.32 \pm 0.87^{\mathrm{a}}$ & $98.47 \pm 0.95^{\mathrm{b}}$ & $104.74 \pm 1.00^{c}$ & $110.16 \pm 0.96^{\mathrm{d}}$ & $113.26 \pm 0.89^{\mathrm{e}}$ & $115.81 \pm 0.74^{f}$ \\
\hline $\mathrm{CP}$ & $78.66 \pm 0.88^{\mathrm{a}}$ & $97.37 \pm 1.11^{\mathrm{b}}$ & $106.95 \pm 1.17^{\mathrm{c}}$ & $115.37 \pm 1.20^{\mathrm{d}}$ & $120.84 \pm 1.14^{\mathrm{e}}$ & $122.94 \pm 1.04^{\mathrm{f}}$ \\
\hline $\mathrm{CBC}$ & $11.87 \pm 0.16^{\mathrm{a}}$ & $13.21 \pm 0.17^{\mathrm{b}}$ & $13.76 \pm-0.15^{\mathrm{c}}$ & $14.26 \pm 0.12^{\mathrm{d}}$ & $14.60 \pm 0.12^{\mathrm{e}}$ & $15.00 \pm 0.18^{\mathrm{f}}$ \\
\hline
\end{tabular}

Note: means in the same line followed by different letters indicate statistical difference $(P<0.05)$ through the Tukey's test. WH: Wither Height; CP: Chest Perimeter; CBC: Cannon Bone Circumference. 
first month of lactation, horse milk offers $5800 \mathrm{Kcal} / \mathrm{kg}$, which decreases from the fifth week. Growth depends of the amount of energy available. Therefore, the levels of energy and ADG decrease simultaneously. On the other hand, the ADG decreases while the BM increases.

Indeed, thus far there are no published studies assessing the development of Quarter Horse suckling foals in tropical conditions, therefore comparisons are difficult. However, similar findings were obtained in a previous study with Thoroughbred foals [5]. In this research the BM increased rapidly, whilst conversely the lowest growth rate was observed for $\mathrm{WH}$ and $\mathrm{CBC}$. In addition after two months a rapid decrease in the growth rate was observed.

Interestingly, the foals were born with a reserve of body fat ( 9.3\% BM). These animals need energy to maintain the body temperature until the mare's milk is established as their primary source of nutrients. During the first hours of life, foals use the carbohydrate reserves present in their liver and muscles [6]. After the first hour, endogenous fat is used as an energy source until the full establishment of nutrition via milk.

Considering the mean weight of an adult Quarter Horse (i.e., $500 \mathrm{~kg}$ ) in Brazil, the weight at birth $(40.9 \mathrm{~kg})$ found in the present study was similar to that reported in previous studies of different European horse breeds, where BM at birth is about $7 \%-13 \%$ of the adult weight [3].

These BM gains are similar to those previously found in studies with thoroughbred foals [7]. Similarly, the development of Quarter Horses and thoroughbred foals presents an average weight gain of $133.3 \mathrm{~kg}$ between the first and fourth month [8]. This finding corroborates the data of the present study, in which a weight gain of $119.8 \mathrm{~kg}$ was detected in the same period.

A previous study with Standardbred foals reported gains in FFM and FM of 160 and $22 \mathrm{~kg}$, respectively [1]. Similarly, the same authors revealed that the FP in young horses of different breeds in Brazil was close to $\sim 10.4 \%$ [9]. These data are similar to those found in the present study, in which the FP ranged from $9.3 \% \pm$ $0.2 \%$ to $9.54 \% \pm 0.02 \%$. It is important highlight that the animals used herein were developing and thus, little adipose tissue had accumulated. Curiously, the FT increased from $1.39 \pm 0.04$ at birth to $1.87 \pm 0.06 \mathrm{~cm}$ at 5 months old. Studies with Standardbred horses found FP values of $8.64 \%$ at birth, 9.20\% after one month and $11.52 \%$ at six months old [1]. A comparison of these data and those obtained in the present study demonstrated that the Quarter Horse breed has a high potential for muscle mass production, since a lower percentage (9.52\%) of fat was detected in the fifth month.

Considering the fact that the skeletal muscle system is responsible for sustaining the horses' body and producing force for locomotion, appropriate development is essential. This development will determine the optimal functionality of the adult horse. If the mare has received adequate nutrition during pregnancy, she may produce milk of high quality and quantity, providing nutrients for the foal until they reach 2 - 3 months of age, when the intake of pasture starts. This combination of mare's milk, grain and pasture provides nutrients that promote satisfactory development in the foal. An adequate intake of these nutrients in this phase of the life is essentialfor satisfactory development.

The biometric indices such as WH, CP, and CBC can indicate whether there is a balance in foals' development, and based on these indices some adjustments in the management of animals may be adopted. In fact, there are studies with another breed of horses that demonstrated significant difference between these indices and the athletic performance of the animals [10].

Based on previous study there is not a single growth rate that is desirable for all types of horses [11]. In that study they highlighted that mineral imbalances, both excesses and deficiencies, and a high energy diet may impair the appropriate growth rate. In addition, genetic factors are also influenced by physical activity and nutrition; therefore several parameters need to be adjusted.

Currently, horse breeders desire an optimal level of animal development without problems or dysfunctions. However, an unbalanced diet may impair proper body growth. Therefore, planning based on specific growth curves could be adopted in order to monitor the development of the animal. Previous studies with thoroughbred horses in different regions of the world (i.e., America, India, England, Australia and New Zealand) between 1996 and 2006 detected significant differences in the patterns of development in these different populations [12]. These authors concluded that in order to obtain good results, specific growth curves could be created specifically for each region.

Finally, no growth abnormalities, such as poor bone formation, limb deviations or joint problems, were observed in the animals during the study. The results obtained in this experiment reflect the correct management systems adopted in the breeding shed where the study was conducted. On the property in question, foals and 
mares are constantly grazing freely and performing physical activities, which favor the accumulation of FFM and low levels of fat.

\section{Conclusion}

In conclusion, suckling Quarter Horse foals accumulate high amounts of FFM during the first five months of life. Due to these adaptations of body composition, appropriate nutritional planning should be adopted in order to maximize the athletic potential of these animals. This study reports preliminary data and seeks to stimulate further studies to determine the parameters of development of suckling foals. This information will be useful in terms of monitoring biometric indices, avoiding imbalances and achieving the animals' best possible performance.

\section{Acknowledgements}

The authors would like to thank Guabi Nutrição Animal and the Uberaba Farm for providing the animals, as well as the workers who contributed to this study.

\section{References}

[1] MansoFilho, H.C., Mckeever, K.H., Gordon, M.E., Manso, H.E., Lagakos, W.S., Wu, G. and Watford, M. (2009) Developmental Changes in the Concentrations of Glutamine and Other Amino Acids in Plasma and Skeletal Muscle of the Standardbred Foal. Journal of Animal Science, 87, 2528-2535. http://dx.doi.org/10.2527/jas.2009-1845

[2] Westervelt, R.G., Stouffer, J.R., Hintz, H.F. and Schryver, H.F. (1976) Estimating Fatness in Horses and Ponies. Journal of Animal Science, 43, 781-785.

[3] Julliand, V. and Martin-Rosset, W. (2005) The Growing Horse: Nutrition and Prevention of Growth Disorders. EAAP Scientific Series, Dijon.

[4] Lawrence, L.A. and Lawrence, T.J. (2009) Advances in Equine Nutrition. 1st Edition, Nottingham University Press, Nottingham.

[5] Luszczynski, J. and Pieszka, M. (2011) Growth Rate of Thoroughbred Horses During First Six Months of Life. Iranian Journal of Applied Animal Science, 1, 131-134.

[6] Ousey, J.C., McArthurs, A.J. and Rossdale, P.D. (1991) Metabolic Changes in Thoroughbred and Pony Foals during the First 24 h Post-Partum. Journal of Reproduction and Fertility, 44, 561-570.

[7] Hintz, H.F., Hintz, R.L. and Van Vleck, L.D. (1979) Growth Rate of Thoroughbreds: Effect of Age of Dam, Year and Month of Birth, and Sex of Foal. Journal of Animal Science, 48, 480-487.

[8] Thompson, K.N., Baker, J.P. and Jackson, S.G. (1988) The Influence of Supplemental Feed on Growth and Bone Development of Nursing Foals. Journal of Animal Science, 66, 1692-1696.

[9] Manso Filho, H.C., Manso, H.E.C.C., Ferreira, L.M.C., Santiago, T.A., Wanderley, E.K. and Abreu, J.M.G. (2009) Percentagem de Gordura de Cavalos Criados em Região Tropical. Acta ScientiaeVeterinariae, 37, 239-243.

[10] Pieszka, M., Luszynski, J. and Lipiec, K. (2007) Biometrical Analysis of Arabian Foals and Their Latter Successes in Shows and on Race Track. Lucrari Stiintifice Zootehniesi Biotehnologii, 40, 209-216.

[11] Pagan, J.D. and Nash, D. (2009) Managing Growth to Produce a Sound Athletic Horse. Advances in Equine Nutrition, 4, 246-258.

[12] Brown-Douglas, C.G. and Pagan, J.D. (2009) Advances in Equine Nutrition. 1st Edition, Nottingham University Press, Nottingham. 
Scientific Research Publishing (SCIRP) is one of the largest Open Access journal publishers. It is currently publishing more than 200 open access, online, peer-reviewed journals covering a wide range of academic disciplines. SCIRP serves the worldwide academic communities and contributes to the progress and application of science with its publication.

Other selected journals from SCIRP are listed as below. Submit your manuscript to us via either submit@scirp.org or Online Submission Portal.
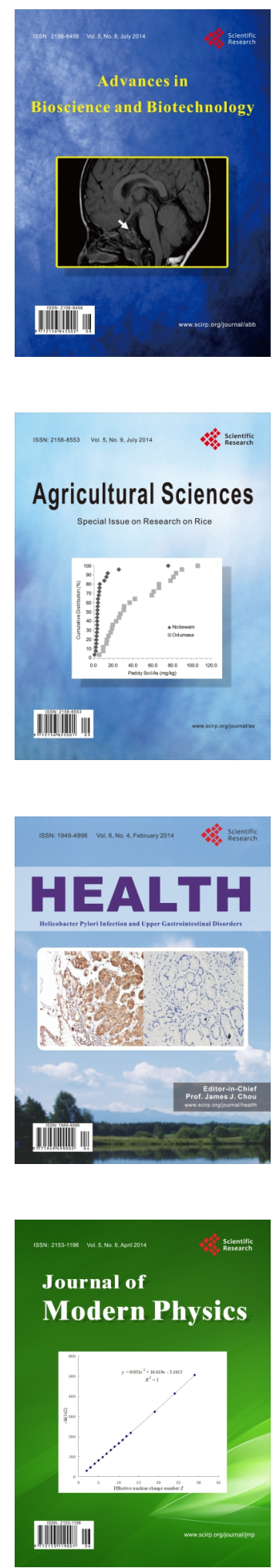
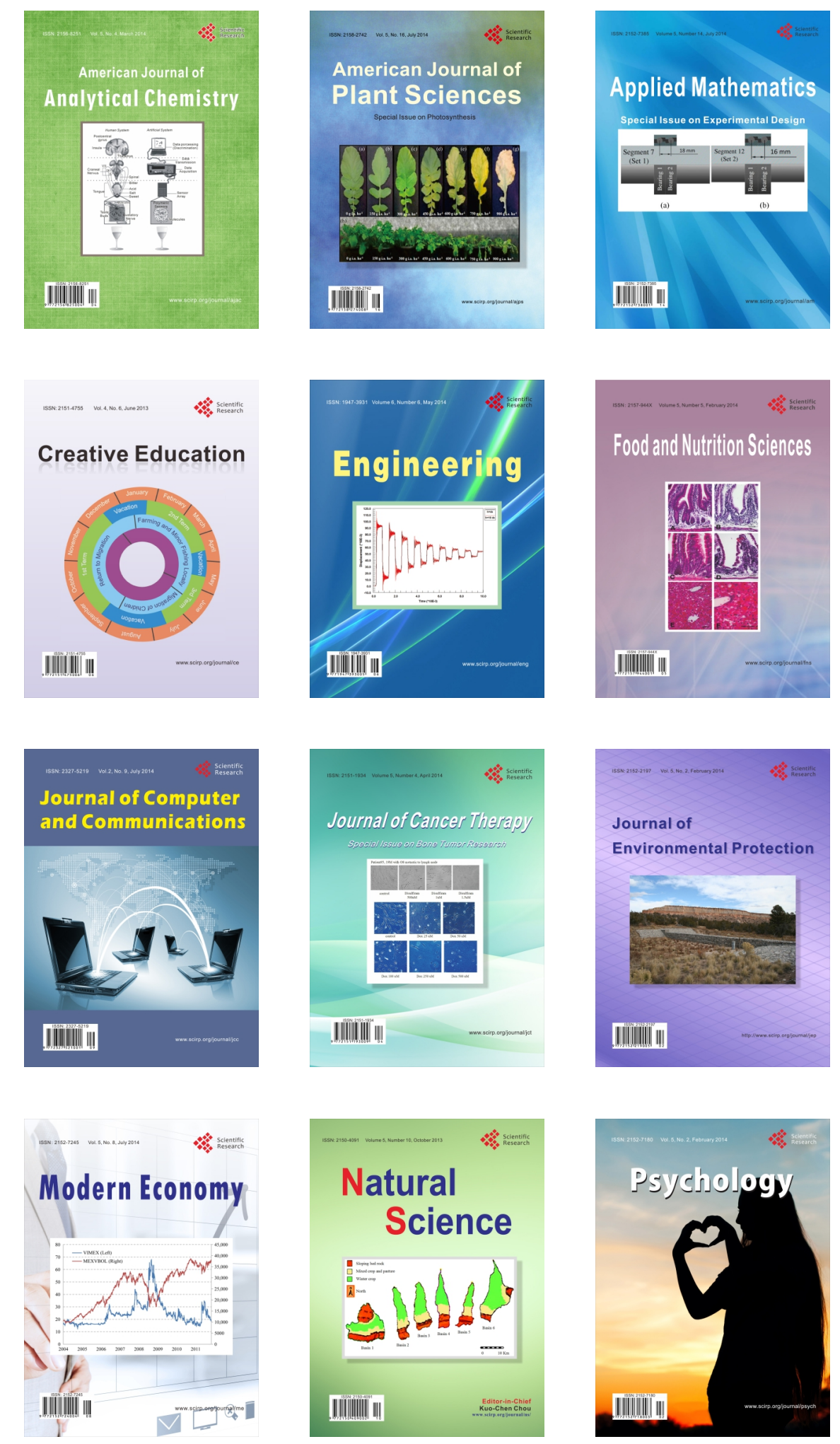